\title{
SÉRIE "FRONTEIRAS": A VISÃO DO JORNAL NACIONAL SOBRE AS FRONTEIRAS BRASILEIRAS
}


SÉRIE “FRONTEIRAS": A VISÃO DO JORNAL NACIONAL SOBRE AS

FRONTEIRAS BRASILEIRAS

Resumo:

O presente trabalho se propõe a analisar a série de reportagens especiais "Fronteiras", veiculada no Jornal Nacional, da Rede Globo de Televisão, com o intuito de entender como a ação da mídia nacional reforça o imaginário da violência e da ilegalidade nas fronteiras brasileiras.

Palavras chave: Fronteiras; Jornal Nacional; Violência

SERIE "FRONTEIRAS": THE VISION OF THE JORNAL NACIONAL ABOUT THE BRAZILIAN BORDERS

Abstract:

This paper aims to analyze the series of special reports "Fronteiras", conveyed at Jornal Nacional, of the Rede Globo de Televisão, with the intention of understand how the action of national media reinforces the imaginary of violence and illegality on the Brazilian borders.

Keywords: Borders; Jornal Nacional; Violence

SERIE “FRONTEIRAS”: LA VISIÓN DEL JORNAL NACIONAL SOBRE LAS FRONTERAS BRASILEÑAS

Resumen:

El presente trabajo propone un análisis de la serie de reportajes especiales "Fronteiras", transmitida en el Jornal Nacional, de Rede Globo de Televisão, con el objetivo de entender como la acción de la media nacional refuerza el imaginario de la violencia y de la ilegalidad en las fronteras brasileñas.

Palabras Clave: Fronteras; Jornal Nacional; Violencia 


\section{INTRODUÇÃO}

O Brasil é o maior país sul-americano e possui 15.735 quilômetros de fronteiras terrestres com dez nações da América do Sul. Com exceção do Chile e do Equador, todos os países do continente fazem fronteira com o Brasil. A colonização do Brasil e a substituição das populações aborígenes pelos imigrantes europeus e africanos teve como ponto de partida o litoral Atlântico. Os sertões a oeste da Serra do Mar foram, na maioria dos casos, os últimos rincões a serem ocupados pelas populações migrantes. Os limites nacionais são, portanto, demarcações recentes e forjaram-se por diversos tratados territoriais entre as coroas portuguesas e espanholas.

As bordas continentais brasileiras revelam ambientes sociais, econômicos, culturais, étnicos e geográficos totalmente distintos entre si, mas que também acumulam semelhanças: as baixas densidades populacionais (com raros casos de cidades com mais de 100 mil habitantes) e a recorrente acusação de relacionamento com as atividades criminosas (violência, contrabando, descaminho, terrorismo, biopirataria, etc.) são exemplos disso. Segundo Silveira, "as fronteiras internacionais brasileiras (...) são sociedades de formação recente, estrutura instável, compostas de migrantes, apátridas e excluídos em diversos sentidos".

Desse modo, a comunicação nacional e internacional trabalha com a hipótese de impossibilidade de existência pacífica e lícita nas regiões de fronteira e mantém o imaginário a respeito desses locais calcado na desordem em contraposição à legalidade de origem positivista proposta pelos media. $\mathrm{O}$ ator social vive na dicotomia entre o Estado - e, consequentemente, da crise das instituições - e a sociedade - caótica que deambula pelas fronteiras e pelas periferias metropolitanas.

Assim, - distante de compreender o aspecto transitório de uma identidade, referenda-se reiteradamente o seu caráter, sua permanência ou adequação a um imaginário congelado no tempo, conforme os conceitos de Silveira sobre a ambivalência na cobertura das periferias nacionais:

É difícil não relacionar certa prática jornalística com o momento burocrático. Ao alinhar-se tão rigidamente com a perspectiva de que o poder instituído constrói e ponderando sobre os modos de ver, sugere-se que o jornalismo está se apropriando de uma tarefa do poder instituído ao construir juízos através da noticiabilidade. (2010, p.4)

Analisaremos a série de reportagens intitulada "Fronteiras", que foi ao ar durante cinco noites do final do mês de maio ao início do mês de junho pelo Jornal Nacional. A série de reportagens foi produzida pelos jornalistas César Tralli, Robinson Cerântula e Fernando Ferro. Em 45 dias, os jornalistas percorreram grande parte dos cerca de 15 mil quilômetros de fronteira terrestre do Brasil. Já na "cabeça" da primeira reportagem, a âncora Fátima Bernardes sinaliza que as áreas fronteiriças são "vulneráveis ao contrabando, às armas e às 
drogas" e que "essa fragilidade está ligada diretamente à violência e à insegurança pública” na região.

\section{METODOLOGIA}

O objeto de análise no presente artigo foi a série de reportagens especiais intitulada "Fronteiras", veiculada no Jornal Nacional, da Rede Globo de Televisão, do dia 31/05 ao 03/06 do presente ano. A escolha do objeto foi motivada devido ao enquadramento no qual foi construído o discurso da reportagem - unicamente baseado na violência e nas contravenções legais das regiões de fronteira com o Brasil - e pelo Jornal Nacional se constituir como uma dos principais formadores de opinião do país, uma vez que, de acordo com Mello, é assistido diariamente por cerca de 80 milhões dos 183,9 milhões de habitantes (IBGE, 2011) do Brasil, o que transforma em espectadores do dado telejornal 43,5\% da população total do país.

O corpus dessa pesquisa corresponde, portanto, as cinco reportagens veiculadas no horário nobre da televisão brasileira, no período acima referenciado. Para análise detalhada, foram selecionadas as duas primeiras reportagens, nas quais verificaremos a presença de marcadores como violência, contrabando, ilegalidade e outros que igualmente denotem a construção de um discurso calcado em torno da necessidade de guarnecer as fronteiras e de expurgar qualquer índice de ilegalidade, personificado, nesta dada cobertura, na figura do vizinho estrangeiro, e da impossibilidade de existência de vida lícita no local.

Por fim, este artigo faz parte de um projeto maior intitulado "Ambivalência de fronteiras e favelas na cobertura jornalística", coordenado pela professora doutora Ada Cristina Machado da Silveira e desenvolvido pelo Grupo de Pesquisa em Comunicação, Identidades e Fronteiras da Universidade Federal de Santa Maria (UFSM).

\section{REFERENCIAL TEÓRICO}

O telejornalismo, assim como os outros gêneros jornalísticos, constrói um discurso que referencia o mundo real, porém trata-se de um recorte de uma dada realidade, enquadrado conforme as posições editoriais do veículo de comunicação e os pontos de vista do sujeito envolvido na construção do discurso televisivo.

Esse discurso, porém, não é constituído apenas de escolhas linguísticas e imagéticas. A comunicação televisual está ancorada também em um tempo e espaço, é representada por/e representa atores sociais e se vale ainda de outro dispositivo subjetivo, que vai além da sintaxe, que é a tonalização do discurso. 
De acordo com Curvello e Duarte, "Tal dispositivo diz respeito à conferência de um tom ou combinatória tonal ao discurso enunciado, ou seja, de um ponto de vista a partir do qual sua narrativa quer ser reconhecida" (2009, p.63). Para os autores, esse tonalização consiste em uma decisão estratégica intrínseca à instância da enunciação, pois além de demarcar a presença dos enunciatários, faz referência à proposta de interação que o dado produto audiovisual pretende realizar junto aos seus interlocutores.

Além dos já citados dispositivos que compõem a ordem discursiva, há ainda a presença, segundo os autores, de outros elementos extragramaticais sem os quais o enunciado se faz incompleto. São eles os enquadramentos de câmera, os recursos de edição de som e de imagem, os registros de falas e a posterior seleção do material a ser utilizado, em um processo denominado decupagem, a escolha dos cenários, dos figurinos, dos jogos de luz, entre outros. O tom fundante do telejornal é o da seriedade, através do qual se busca transmitir efeitos de objetividade, neutralidade, imparcialidade e, principalmente, de autenticidade e verossimilhança. Para isso, tem-se a presença do jornalista no local do desenrolar do fato, com a promessa do testemunho pessoal, muito além do captável pela câmera. De acordo com Jost:

Na falta de imagens, na falta de ter podido captar o acontecimento no momento em que ele se dava, o jornalista recorre à confiança que se credita àquele que viu. No caso da restituição, a verdade concedida à reportagem estava ligada à sua natureza semiótica: a imagem eletrônica sendo uma impressão, um indício, ela tinha um laço existencial com a realidade de onde ela tirava sua força. Donde uma promessa de autenticidade. (2009, p.23)

Além da testemunhalidade, outro recurso que é bastante usado no gênero telejornalístico é o da câmera escondida. A câmera fica discretamente escondida em algum detalhe do vestuário do jornalista e este se presta ao papel de uma pessoa comum, que busca informações através de uma conversa informal e, por muitas vezes, falsamente despropositada. A câmera toma, então, o lugar do jornalista, que se torna apenas o condutor da conversa, que ora pergunta ora responde, enquanto é do dispositivo eletrônico a responsabilidade pela apreensão da realidade. Os envolvidos nas filmagens ocultas, na maioria dos casos, não percebem que falam a um veículo midiático e se despem de qualquer artifício de defesa pessoal. No meio profissional, a câmera escondida é o máximo da objetividade (JOST, 2009).

O fato apreendido tanto pelo recurso de testemunhalidade, quanto pelo ocultamento de câmera é uma versão da realidade, é apenas a apreensão do visível no momento. Não explora a realidade, nem a contextualiza. Apenas exibe o capturável em um tempo e um espaço previamente determinado. 
Mouillaud (apud LEAL, 2009, p.92) diz que, os acontecimentos transformados em fatos jornalísticos podem se tornar "a sombra projetada de um conceito produzido pelo sistema de informação". Ao construir a notícia o jornalismo opera uma leitura da realidade e a enquadra em uma estrutura organizativa. A preferência por determinado aspecto do conjunto de referências que contextualizam o fato e tornam possível a visibilidade desejada, porém, podem refletir na deturpação do acontecimento. (LEAL, 2009)

\section{DADOS ANALISADOS}

\begin{tabular}{|c|c|}
\hline Jornal & Jornal Nacional \\
\hline Data & $23 / 05 / 2011$ \\
\hline Título & Fronteiras do Brasil são passagens fáceis para criminosos de dez países \\
\hline Editoria & Polícia / Segurança Pública \\
\hline Destaque & Reportagem Especial \\
\hline Assinatura & César Tralli, Robinson Cerântula e Fernando Ferro \\
\hline Infografia & Uma \\
\hline Descrição da Infografia & $\begin{array}{l}\text { Mapa de rota clandestina no entorno do Posto da Receita Federal, construído a } \\
\text { partir de imagens de satélite do google. }\end{array}$ \\
\hline Chamada & $\begin{array}{l}\text { Nesta segunda-feira (30), começa com a primeira reportagem de uma série sobre } \\
\text { as fronteiras brasileiras. Nove anos atrás, em um trabalho semelhante a este, } \\
\text { mostramos como essas áreas eram vulneráveis ao contrabando, às armas e às } \\
\text { drogas. E como essa fragilidade se ligava diretamente à violência e à insegurança } \\
\text { pública. } \\
\text { A série que você vai acompanhar nesta semana é resultado de uma viagem de } 45 \\
\text { dias dos repórteres César Tralli, Robinson Cerântula e Fernando Ferro. O que eles } \\
\text { encontraram é ainda mais preocupante. }\end{array}$ \\
\hline Pessoas referidas & $\begin{array}{l}\text { Equipe de reportagem, sacoleiros, policiais, fiscais, pistoleiro, Polícia Federal, } \\
\text { Polícia Militar e Exército. }\end{array}$ \\
\hline Fontes explicitadas & $\begin{array}{l}\text { Delegado da Polícia Federal do Mato Grosso, Inspetor Chefe de Mundo Novo, } \\
\text { Fiscais da Receita Federal, Policiais Militares, }\end{array}$ \\
\hline Argumento discursivo & $\begin{array}{l}\text { A área de Fronteira é mal vigiada, os postos da Polícia e da Receita Federal que } \\
\text { existem no local são insuficientes para o controle das fronteiras que, segundo } \\
\text { o argumento discursivo da reportagem, fortalece o tráfico, o contrabando e a } \\
\text { violência. }\end{array}$ \\
\hline Marcadores argumentativos & $\begin{array}{l}\text { Armas ( } 1 x) \text {, assassinato e variantes }(2 x) \text {, crime (1x), cocaína ( } 4 x) \text {, contrabando } \\
\text { e variantes }(3 x) \text {, drogas ( } 1 x) \text {, fiscalização }(6 x) \text {, fronteira (1x), insegurança (1x), } \\
\text { violência }(2 x) \text {, muamba }(2 x) \text {, cocaína ( } 1 x) \text {, tráfico e variantes (1x), Receita Federal } \\
(4 x)\end{array}$ \\
\hline Transcrição de destaques & $\begin{array}{l}\text { "Dois carros zero quilômetro e um disfarce quase perfeito: dentro das carroce- } \\
\text { rias. São máquinas fotográficas, lentes, baterias, equipamentos eletrônicos. É um } \\
\text { carro zerinho adaptado para o transporte de muamba." } \\
\text { "E de um extremo ao outro por onde a equipe passou, em } 45 \text { dias de viagem, } \\
\text { uma situação se repetiu: salas vazias, sem ninguém. Mesmo uma sala de vigilân- } \\
\text { cia, o prédio estava completamente vazio. Foi o posto de Barra do Quaraí, que } \\
\text { separa o Rio grande do Sul do Uruguai." }\end{array}$ \\
\hline
\end{tabular}




\section{Matéria 2}

\begin{tabular}{|c|c|}
\hline Jornal & Jornal Nacional \\
\hline Data & $24 / 05 / 2011$ \\
\hline Título & Corrupção facilita ação de criminosos nas fronteiras brasileiras \\
\hline Editoria & Polícia / Segurança Pública \\
\hline Destaque & Reportagem Especial \\
\hline Assinatura & César Tralli, Robinson Cerântula e Fernando Ferro \\
\hline Infografia & Duas \\
\hline Descrição da Infografia & $\begin{array}{l}\text { Mapa terrestre mostrando o trajeto feito pela equipe de reportagem, } \\
\text { de Foz do Iguaçu (PR) a Ponta Porã (MS); Mostra os portos clandes- } \\
\text { tinos em números, entre as cidades de Foz do Iguaçu (PR) e Guaíra } \\
\text { (PR). }\end{array}$ \\
\hline Chamada & $\begin{array}{l}\text { Na segunda reportagem da série especial sobre as fronteiras terres- } \\
\text { tres brasileiras, os repórteres Cesar Tralli, Robinson Cerântula e Fer- } \\
\text { nando Ferro mostram o comércio ilegal de armas, a oferta de drogas, } \\
\text { o contrabando nos rios e até a falsificação de selos do Inmetro. Tudo } \\
\text { isso facilitado pela corrupção. }\end{array}$ \\
\hline Pessoas referidas & $\begin{array}{l}\text { Vendedor, policial, produtores da reportagem, Polícia Federal, crimi- } \\
\text { noso brasileiro, promotor, militares. }\end{array}$ \\
\hline Fontes explicitadas & $\begin{array}{l}\text { Membro da Associação Brasileira de Combate a Falsificação, fun- } \\
\text { cionário do Inmetro, agente da Polícia Federal, Promotor de Justiça. }\end{array}$ \\
\hline Argumento discursivo & $\begin{array}{l}\text { As armas que vem do Paraguai são utilizadas nos crimes realizados } \\
\text { no Brasil. A mercadoria vendida nas lojas populares são, em sua maio- } \\
\text { ria, falsificadas. }\end{array}$ \\
\hline Marcadores argumentativos & 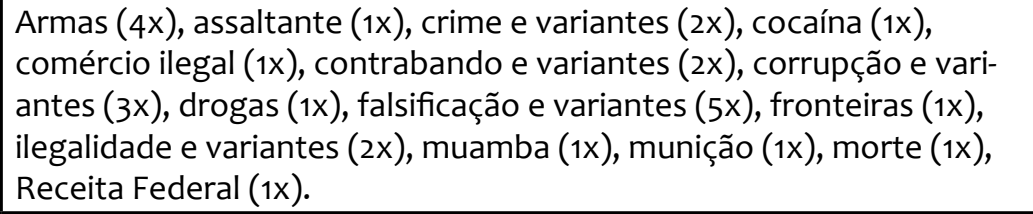 \\
\hline Transcrição de destaques & $\begin{array}{l}\text { Onde tem rua de comércio popular no Paraguai quase sempre tem } \\
\text { uma loja de arma. São } 32 \text { só na fronteira com o Paraná. À venda, há } \\
\text { pistolas automáticas de grande precisão, as mesmas usadas no Brasil } \\
\text { para assaltar e matar." } \\
\text { "Nossos produtores deram uma voltinha no centro. Em apenas dez } \\
\text { minutos, ouviram todo tipo de oferta: munição, remédio falso, cocaí- } \\
\text { na.” }\end{array}$ \\
\hline
\end{tabular}

\section{INTERPRETAÇÃO DOS DADOS}

À primeira vista, é necessário relacionar o título da série de reportagens com o conteúdo das mesmas. O chamado "Fronteiras" expõe uma ótica reducionista por parte da equipe de profissionais de comunicação: se o teor dos registros trata apenas dos temas recorrentes do jornalismo em relação às fronteiras - a violência, o contrabando e as contravenções legais -, por que o título remete a todo um espaço diverso tal como são os limites nacionais? 
A primeira reportagem da série começa com a fala da âncora do Jornal Nacional, a jornalista Fátima Bernardes, que explicita que o tema da série de reportagens é seguidamente revisitado pelo programa:

"Nove anos atrás, em um trabalho semelhante a este, mostramos como essas áreas eram vulneráveis ao contrabando, às armas e às drogas. E como essa fragilidade se ligava diretamente à violência e à insegurança pública." (repórter, 2011)

Em seguida, o âncora e editor-chefe do JN, William Bonner, diz que o que foi encontrado nos dias de hoje é ainda mais preocupante. A vinheta, produzida com o auxílio das tecnologias de infografia, desenha um mapa das fronteiras nacionais com uma linha vermelha. $O$ título da reportagem aparece logo depois, no centro da tela, sublinhado pela mesma linha vermelha.

No começo da reportagem, o repórter César Tralli narra em off duas apreensões feitas pela Polícia Federal, uma de câmeras digitais e outra de cigarros falsificados e cocaína. Segundo a o texto da reportagem, as mercadorias foram confiscadas em estradas distantes da linha de fronteira, ou seja, os contrabandistas já haviam passado pelas aduanas. Em entrevista, o delegado Chang Fan, da Polícia Federal do Mato Grosso do Sul, explica que os criminosos têm uma organização sofisticada. Todo o texto e as cenas anteriores podem ser resumidos na próxima fala de Tralli: "E não é nem um pouco difícil entrar no Brasil." Durante as próximas cenas, a reportagem percorre as cidades de Corumbá (MS), Mundo Novo (MS), Salto Del Guairá (no Paraguai), Barra do Quaraí (RS) e Tabatinga (AM). Em cada mudança de localidade, um mapa aparece na tela com o trajeto entre as cidades visitadas, que são identificadas por um símbolo que se assemelha a um alvo. O clima de tensão é reforçado pela trilha sonora, que ganha intensidade nesses momentos.

A segunda reportagem começa mostrando imagens da região de comércio de alguma cidade paraguaia na fronteira com o Brasil. Com uma música de ação ao fundo, o repórter César Tralli (2010) narra: "Onde tem rua de comércio popular no Paraguai quase sempre tem uma loja de armas. São 32 só na fronteira com o Paraná. À venda, pistolas automáticas de grande precisão. As mesmas usadas no Brasil para assaltar e matar". O argumento discursivo dá a entender que as armas usadas nos crimes praticados no Brasil são originárias dos países vizinhos. Porém, conforme o relatório da Secretaria de Segurança Pública do Rio de Janeiro, de 2005, 28\% das armas apreendidas naquele estado provinham do contrabando. Em seguida, uma câmera escondida mostra um lojista paraguaio garantindo que pode entregar as armas em Foz do Iguaçu. Segundo Jost (2009), a câmera escondida é, no meio profissional jornalístico, o máximo de objetividade, pois o repórter se torna mero condutor da conversa, enquanto a câmera assume a responsabilidade de captar a "realidade" que se deseja evidenciar. 
A seguir, um policial da Força Nacional de Segurança afirma, novamente, que o efetivo das forças de combate à corrupção é insuficiente. Na divisa de Ponta Porã (MS) com Pedro Juan Caballero, no Paraguai, o recurso da câmera escondida é novamente utilizado. As duas cidades são separadas por uma avenida. Tralli narra que os produtores da reportagem "deram uma voltinha no centro". Prossegue: "em apenas dez minutos ouviram todo o tipo de oferta. Munição, remédio falso, cocaína". Um jovem paraguaio aparece no vídeo e diz: "é da pura mesmo". A reportagem passa a tratar da falsificação de selos do INMETRO e o uso deles em capacetes contrabandeados. O assunto é mote para o próximo tema, o contrabando de cigarros. Sob o fundo de uma música de suspense, o repórter narra: "saúde em jogo também com o cigarro pirateado". Um representante da Associação Brasileira de Combate à Falsificação mostra os selos falsificados da Receita Federal do Brasil nos maços de cigarro. Em um helicóptero, a reportagem mostra um barco carregado de caixas atravessando o rio Paraná e uma infografia mostra os diversos portos clandestinos no lago da represa Itaipu. Em seguida, a reportagem mostra imagens noturnas cedidas pela Polícia Federal. Novamente, um agente afirma que o efetivo não é suficiente para todas as operações.

Em seguida, o repórter César Tralli entrevista um brasileiro, gerente de porto clandestino em Foz do Iguaçu. O homem, em um ambiente escuro e com a voz modulada pela edição da reportagem, afirma que as mercadorias são distribuídas para todo o Brasil e, para isso, paga propina para policiais. A reportagem termina com imagens do barco atravessando rio Paraná e da loja de armas no Paraguai, sob o fundo de música de suspense.

No final de cada matéria, já na bancada do JN, os apresentadores descrevem o contraponto dado pelas autoridades. No caso da primeira, o Exército, a Polícia Federal, e a Receita Federal prestam esclarecimentos. Na segunda reportagem, a Receita Federal e a Secretaria de Segurança Pública do Paraná deram explicações.

\section{CONSIDERAÇÕES}

Uma das explicações possíveis para este tipo de agendamento é que o jornalismo, por sua tradição positivista, privilegia os fatos em detrimento das estruturas que os fazem acontecer. Ou seja: a série "Fronteiras" noticia as apreensões, as estatísticas, a deficiência de infraestrutura dos instrumentos estatais de coerção do crime - mas não informa ao espectador que tais fatos ou predicados são produtos da demanda nacional por bens de consumo contrabandeados ou de drogas, por exemplo. A única explicação dada pelas reportagens para a situação "preocupante" dos limites nacionais seria a falta de fiscalização por parte do poder público.

Além disso, ignora a existência de vida lícita no local, reduzindo toda a diversidade cultural às práticas de ilegalidade que ocorrem na região. Genro Filho, em sua teoria marxista do jornalismo, diz que o senso comum reprodu- 
zido pelo jornalismo, como é o caso da visão reducionista na qual as questões fronteiras referem-se apenas à violência, é tida a partir da "significação meramente "funcional" no universo social vivido" $(1989,189)$. Diz ainda que "a base na qual o fato será assentado e contextualizado tende a reproduzir de maneira latente a universalidade social tal como é vivida imediatamente" (GENRO FILHO, 1989, 189.). De acordo com essa teoria, o senso comum das classes dominantes é fomentado e reproduzido pelo jornalismo nacional e introduzido na vivência social coletiva, o que dificulta na formação de identidades locais e regionais. O trabalho não visa negar que as práticas evidenciadas pela série de reportagens não ocorram. Pretende propor uma discussão acerca das abordagens jornalísticas sobre as fronteiras e as possibilidades de, através de uma visão mais ampla, fazer com que o retrato dos moradores dessa região não seja submetido à generalizações apressadas e ao senso comum, para que, assim, possam se reconhecer como atores sociais dotados de identidade própria, de cultura e também da diversidade que é típica das áreas de encontro entre os países.

\section{REFERÊNCIAS}

DUARTE, E.; CURVELLO, V. Telejornais: quem dá o tom? In: GOMES, I. M. (Org.) Televisão e Realidade. Salvador: EDUFBA, 2009.

GENRO FILHO, A. O segredo da pirâmide: para uma teoria marxista do jornalismo. Porto Alegre: Ortiz, 1989.

JOST, F. Que significa falar de "realidade" para televisão? In: GOMES, I. M. (Org.) Televisão e Realidade. Salvador: EDUFBA, 2009.

LEAL, B. Telejornalismo e autenticação do real: estratégias, espaços e acontecimentos. In: GOMES, I. M. (Org.) Televisão e Realidade. Salvador: EDUFBA, 2009. GOVERNO DO ESTADO DO RIO DE JANEIRO. Fontes de abastecimento do mercado criminal de armas. Disponível em: < http://www.rolim.com.br/2002/_pdfs/origemdaarma.pdf >. Data de acesso: 23/08/2011.

SILVEIRA, A.M. Modos de ver e devorar o outro: a ambivalência na cobertura jornalística das periferias. Revista GHREBH, v.1, n.14, 2009. <htpp://revista.cisc.org,br/ghrebh/index.php?journal=ghrebh\&page $=$ article $\&$ op $=$ download\&path $\% 5 \%$ B $D=58$ \&path\% $5 \% 5 \mathrm{D}=63>$ Data de acesso: 20/08/2011. 


\section{Ada Cristina Machado Silveira}

Possui graduação em Comunicação Social Jornalismo pela Universidade do Vale do Rio dos Sinos (1982), é Magister en Periodisme i Ciències de la Comunicació - Universitat Autònoma de BarceIona (1998), com mestrado em Extensão Rural pela Universidade Federal de Santa Maria (1992), Doctorado en Periodismo - Universitat Autònoma de Barcelona (2000) e com estágio pós-doutoral na Sorbonne III (La Nouvelle). Atualmente é Professor Associado II da Universidade Federal de Santa Maria e pesquisadora do CNPq.

\section{Anelise Schütz Dias}

Acadêmica do curso de Jornalismo da Universidade Federal de Santa Maria e pesquisadora vinculada ao grupo de pesquisa em Comunicação, Identidades e Fronteiras. Atualmente participa de programa de mobilidade acadêmica com a Universidade do Algarve, Faro, Portugal.

\section{Gregório Lopes Mascarenhas}

Estudante de Comunicação Social - Jornalismo da Universidade Federal de Santa Maria. Bolsista de iniciação científica. Atualmente participa de programa de mobilidade acadêmica com a Universidade do Algarve, Faro, Portugal. 